\title{
Review Article \\ Preventive Maintenance Optimization in Healthcare Domain: Status of Research and Perspective
}

\author{
H. Mahfoud, A. El Barkany, and A. El Biyaali \\ Faculty of Sciences and Techniques, Mechanical Engineering Laboratory, Sidi Mohammed Ben Abdellah University, 2202 Fes, Morocco \\ Correspondence should be addressed to H. Mahfoud; hassana.mahfoud@usmba.ac.ma
}

Received 6 March 2016; Revised 24 June 2016; Accepted 29 June 2016

Academic Editor: Adiel T. de Almeida

Copyright (C) 2016 H. Mahfoud et al. This is an open access article distributed under the Creative Commons Attribution License, which permits unrestricted use, distribution, and reproduction in any medium, provided the original work is properly cited.

\begin{abstract}
Although medical equipment maintenance has been carefully managed for years, very few in-depth studies have been conducted to evaluate the effectiveness and efficiency of these implemented preventive maintenance strategies, especially after the debate about the credibility of manufacturer's recommendations has increased in the clinical engineering community. Facing the dilemma of merely following manufactures maintenance manual or establishing an evidence-based maintenance, medical equipment maintenance could have exploited an advanced area in operations research which is maintenance optimization research. In this paper, we review and examine carefully the status of application oriented research on preventive maintenance optimization of medical devices. This study addresses preventive healthcare maintenance with a focus on factors influencing the maintenance decision making. The analysis is structured by defining different aspects necessary to construct a maintenance optimization model. We conclusively propose directions to develop suitable tools for better healthcare maintenance management.
\end{abstract}

\section{Introduction}

In the present competitive market, where companies worldwide are tightening their economical belts to diminish costs while assuring high services quality and safety, plant dependability key performance indicators have become an area in which to center initiatives [1]. Recently, companies realize that their competitiveness, performance, and thus their future are sturdily linked to the effectiveness and efficiency of maintenance management $[2,3]$. Therefore, this recognition brings about a radical change of maintenance perception from a "necessary evil" to an "investment opportunity" to be optimized. Maintenance excellence can be achieved by making the rational maintenance decision balancing costs and industrial performance [4]. It is worth mentioning that the amount, multiplicity, sophistication, and costs of medical equipment are abruptly rising, which make that their maintenance complexity and costs also escalate sharply in the last few years [5]. In addition to maintenance expenditure, medical devices (MD) are frequently involved in patient incidents (death or injury) [6]. Therefore, a legal obligation is imposed upon healthcare organizations and clinical engineering to ensure high-level safety and reliability of their medical devices as well as checking maintenance strategies efficiency. In this paper, we address a better part of existing publications on preventive maintenance optimization, particularly applied and validated models in healthcare domain. This study reviews various important aspects of medical equipment maintenance, analyses different research insufficiencies found in healthcare maintenance optimization modeling literature, and proposes directions to develop suitable tools for better medical devices management.

In the interest of drafting a general bibliography on healthcare maintenance optimization problems, we consulted a range of academic databases, mainly Scopus database. And then, we extracted 35 sources related to medical equipment maintenance, based on several combinations of these keywords: Healthcare maintenance, Medical equipment, maintenance optimization, medical strategy effectiveness, and clinical maintenance efficiency. The extracted collection includes articles published between 2000 and 2015, which spans various aspects: maintenance optimization modeling, empirical studies, and risk-based prioritization of medical equipment; see Figure 1 and the Appendix. "Journal of clinical 


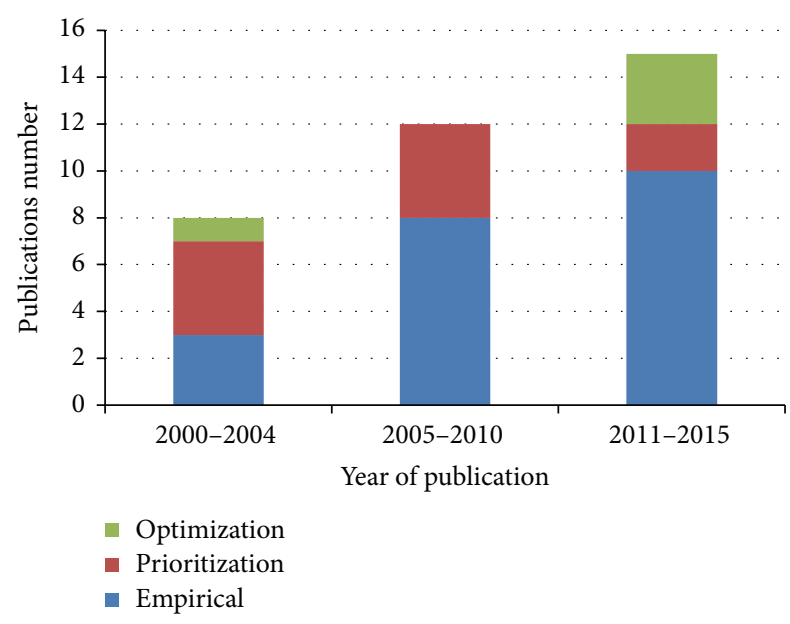

FIGURE 1: Medical equipment maintenance research evolution.

engineering" was singled out, as providing the most coverage on the topic investigated in this study $(20 \%$ of the journal papers). According to the study, only $11 \%$ of researches concern medical equipment maintenance optimization modeling compared with $60 \%$ empirical and $29 \%$ prioritization publications. We deduce that preventive maintenance optimization modeling in healthcare domain is still in its infancy stage and it is an underexplored area in which to focus initiatives to address optimal maintenance strategies.

\section{Maintenance Evolution}

Due to the increasing consciousness of the importance of maintenance management, this process has undergone successive changes over recent years, Figure 2. Until 1960s, run to failure maintenance had been the widespread policy; then, preventive maintenance (PM) concepts appeared and became well known. Time-based maintenance is the first aspect of PM, which consists of scheduled activities of maintaining and parts replacement to avoid unpredicted failures [7-10]. In the second half of 1980 s, condition monitoring technologies were developed and condition-based maintenance (CBM) came out. This policy triggers maintenance activities no more than when there is evidence of deterioration to reduce unnecessary scheduled actions [11-14]. Recently, maintenance management community introduced "prognostics" concept which deals with fault prediction before it happens $[15,16]$. In this context, predictive maintenance $(\mathrm{PdM})$ is a CBM policy that includes prognostics in its decision process. Thus, PdM incorporates more information on assets degradation, in the form of their remaining useful life (RUL) $[17,18]$.

Despite the exponential rising of information technologies supporting these advanced maintenance policies, there are still some issues unaddressed in the literature. According to [19], many optimization models have been developed to choose the optimal policy; however, they are inappropriate for business context. Many researchers arrived at the same conclusion: It is necessary to handle the gap between academic models and real environment applications $[18,20]$. In this context, [21] it is pointed out that the application of maintenance optimization models to medical devices is rather scarce and new. Most of the healthcare organizations merely follow manufacturer's recommendations and do not profit from maintenance excellence in so far as other industries. The majority of researches in this domain just put forward how to evaluate and improve devices reliability in their design or manufacturing phase without considering reliability assessments and maintenance strategies of these pieces of equipment in their operating context. The paper [22] assigned specific failure codes to measure maintenance effectiveness for numerous kinds of medical devices. They concluded that current maintenance strategies are effective but it is not evident whether they are efficient.

\section{Overview of Medical Devices Maintenance Optimization}

Even though many equipment management programs (MEMPs) have been well planned and executed in healthcare organizations for more than 30 years, very few studies investigate the effectiveness of these programs in providing an optimized PM considering reliability, cost, and safety for service delivery.

Several risk-based MEMPs have been already proposed in the literature and are currently in use. The paper [23] implemented a risk-based prioritization tool for preventive maintenance inspections. The PM intervals are assigned according to a risk level of critical devices. The paper [24] drew attention to the necessity of providing a logical basis for determining reasonable and appropriate PM interval tests, taking into account partial failures. Ridgway proposed a risk-based approach to prioritize devices that meet maintenance sensitivity criteria. The paper [25] highlights that one of the most criticized problems of clinical maintenance management is the obsolescence of medical devices. They stressed the inadequacy of life cycle costs mathematical models for critical devices replacement and proposed a fuzzy inference model to include both quantitative and qualitative parameters affecting replacement decisions. The paper [26] developed for the same goal a multicriteria decision model using Macbeth sociotechnical approach based on decision maker's preferences. The proposed model provides not only raking risk levels but also cost benefits analysis. Nevertheless, the decision conference duration and difficulties to concentrate in the criteria assessments are the main weaknesses. The paper [27] presents a multicriteria prioritization technique derived from an analytical hierarchy process using crisp scales that do not handle uncertainty. The paper $[28,29]$ proposes a fuzzy risk-based framework to prioritize $\mathrm{MD}$ and decide the optimal maintenance strategy. The paper [28] tried to overcome the previous works shortcoming that neglected other criteria like economic loss and the uncertainties in expert's judgment issues.

Nevertheless, the single risks assessment used to guide safety and PM activities is a common theme in these methods that are inconsistent aggregation processes and so unable to provide appropriately optimized solutions for stochastic maintenance problems [30]. 


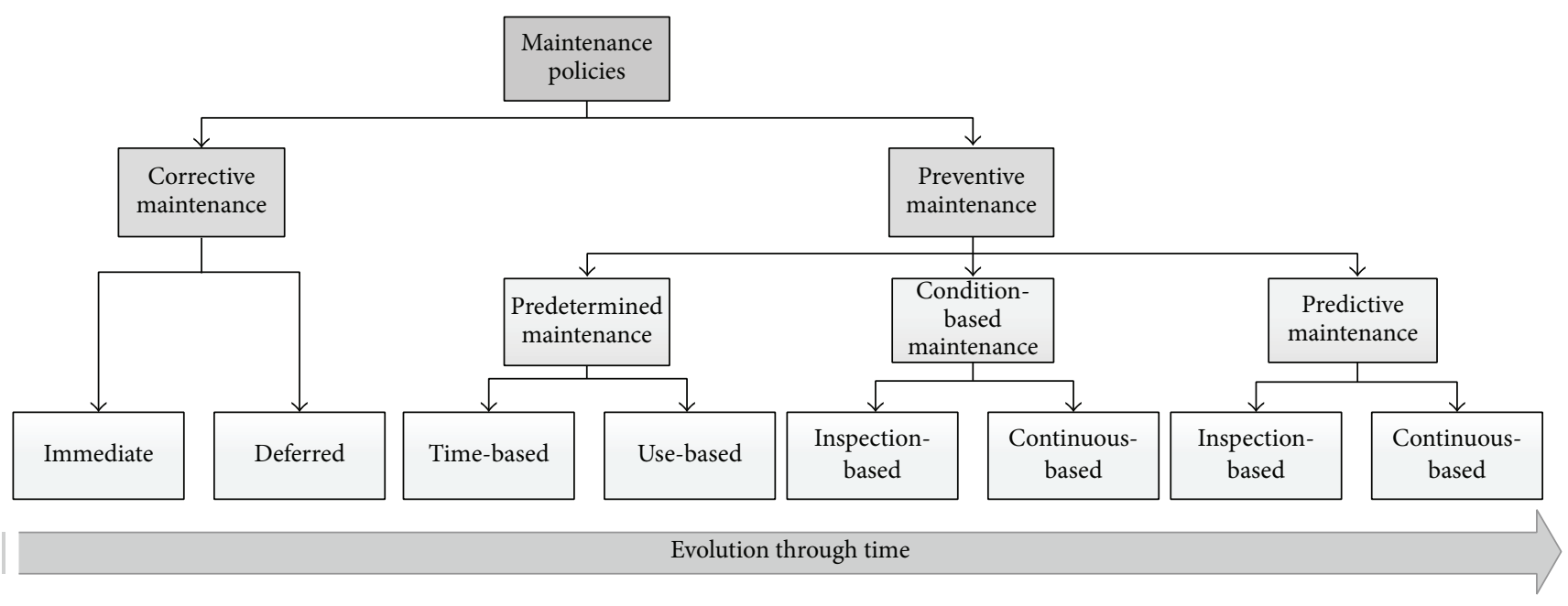

FIGURE 2: Maintenance evolution.

A staid debate has been raised recently among clinical engineers (CE) professionals and researchers about the credibility of manufacturer-recommended PM intervals and whether it is founded on meaningful test data. Ridgway [31] debates the question and stresses the importance of streamlining the current maintenance policies by analyzing the operational reliability of MD. The paper [32] evaluated and analyzed maintenance strategies effect on the survival probability of some MD using exponential distribution approach. The foremost finding of this study is that the equipment flowing strictly the manufacturer's recommended interval for PM is less reliable than the one of the same model with less preventive interventions. That authenticates [31] debate.

This paper focuses on aspects related to preventive maintenance optimization of medical devices. The analysis is structured by defining different classes necessary to construct a maintenance optimization model using the framework in Figure 3.

3.1. Maintenance Concepts. Reliability centered maintenance (RCM) $[33,34]$ and total productive maintenance (TPM) [35, 36] are the eminent maintenance concepts in the literature. They set out the general decision support structure in which maintenance actions and policies are planned. The review has shown that a little has been done to prove the performance of those empirical approaches in the healthcare domain. The paper [37] indicated that keeping track of reasons which trigger repair calls in hospitals would be useful to provide remedial measures. Based on statistics of 9 major causes' categories, the author found that user-related causes represent $10 \%$ of the total and he drew attention to the necessity of adopting RCM methodology in hospitals. Furthermore, [38] studied the relationship between availability of high risk MD and patient outcomes and suggested new maintenance approaches for critical equipment such as TPM to improve the MMS (medical management system). The paper [39] implemented Six Sigma methodology on corrective maintenance process in Jordanian hospitals. It was mentioned in the model that check time, decision time, and delivery time are the key factor influencing the downtime, not maintenance time. The author proposed new $\mathrm{CM}$ procedure to organize the maintenance staff. Even if these approaches are heuristic and time consuming and founded on expert's judgments and experience, they represent a significant step in "getting the most out" of assets such as aeronautics and military applications [40]. The paper [41] asserts that empirical studies may help medical maintenance services elaborate evidence-based strategies for the betterment of their performance levels.

3.2. Maintenance Policies and Actions. Maintenance policies can be usually classified into three categories: preventive, corrective, and condition-based maintenance. As indicated in [42] PM including block and time-based maintenance is the most investigated policy in the literature compared to CBM. $\mathrm{PM}$ is also the widely established policy for medical devices. The paper [24] distinguishes between three different kinds of $\mathrm{MD}$ preventive maintenance: scheduled maintenance $(\mathrm{SM})$, performance verification (PV), and testing safety (TS). Likewise, [22] recapped several types of MD maintenance activities consisting of repair, replacement, or inspections. The paper [5] dispelled a misunderstanding related to $\mathrm{MD}$ maintenance which is "the more maintenance the better" and introduced the analogous concept "evidence-based maintenance." A high completion rate of scheduled maintenance is not a good indicator of maintenance effectiveness (reliabilityavailability-safety) and efficiency (overall costs), to the extent that evidence-based maintenance would be a continual improvement process that analyzes the effectiveness and efficiency of maintenance policy deployed in comparison to outcomes attained.

Although maintenance modeling trend is shifting to CBM and predictive maintenance strategies, this remains an unexplored area in the healthcare domain. In fact, [43] makes evident the efficiency of condition-based maintenance in medical devices through a case study which demonstrates a large cost-benefit of CBM compared with previous policy consisting of reactive and time-based PM. 


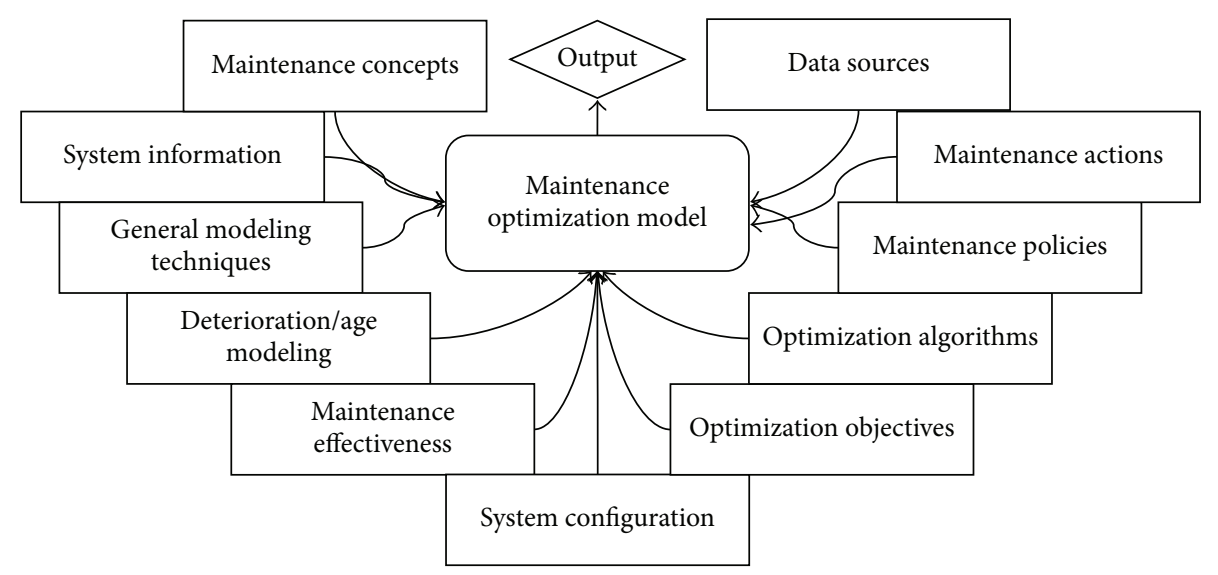

FIGURE 3: Factors affecting preventive maintenance modeling.

3.3. Optimization Objectives. Maintenance optimization is achieved by maximizing or minimizing one or multiple criteria, called objective function. The paper [44] indicates that these objectives can be classified under four captions. The first significant one is ensuring system function, synonym to dependability (reliability, availability, and maintainability) and capability and the second one is ensuring system life and minimizing costs to meet the norms of asset management. Further, guarantying safety is vital, especially in the case of dramatic consequences. Finally, performing maintenance personal management and human well-being is rarely investigated.

Many maintenance objectives have been cited in the literature; however, very few of them have been taken into account in optimization models [42]. The majority of researches in this area seek to optimize one criterion (single-objective optimization), which is typically maintenance costs [45]. In a large amount of these studies, maintainability is not considered because of the common assumption of neglected repair times. Maintenance action duration exclusion sometimes leads to suboptimal solutions. Then again, a limited number of publications that appeared in the literature deal with multiobjective optimization problems adding reliability or availability criterion $[8,11,46]$.

In the healthcare domain, optimization models limited scope by considering a single objective (mainly the overall cost) is another limitation perceived in this review [47-49], which is often not the case of real industrial environment. The paper [5] confirms that, in addition to reliability, safety, and maintenance efficiency measure, availability is an important indicator of maintenance effectiveness. This statement is argued in $[38,50]$ study. Accordingly, multiobjective optimization models remain an underexplored subject for medical equipment. And less attention was paid to determine the key objective criteria to avoid incorrect maintenance model leading to suboptimal solutions.

3.4. Maintenance Effectiveness. It is the degree to which a component's operation condition is restored after a maintenance action is performed. The paper [51] presents a review of different possible reinstatement degree: perfect repair or as good as new (AGAN) maintenance where the failure rate becomes the same as a new component. Minimal repair or as bad as old (ABAO) for that the degradation level is restored to the situation before the maintenance action is executed. These assumptions are the main shortcoming of a wide range of maintenance optimization models in the literature [42, $51,52]$. We find also worse repair which is the maintenance action that causes failure rate decreasing while the worst repair leads to the breakdown of the maintained system. Imperfect maintenance is considered the appropriate maintenance effectiveness representation in real industrial context $[7,45,53]$, where system's operating condition is returned to somewhere between AGAN and ABAO. Brown-and Porchan model, $(p, q)$ rule, improvement factor, and virtual age are some methods among the multitude ones developed to model this kind of maintenance [51].

For medical devices, few works were developed to assess maintenance effectiveness. In [48] mathematical optimization model of periodic inspections was founded on the same simple assumption of perfect maintenance (AGAN). Later, [32] presented an age-dependent model to evaluate and analyze maintenance strategies (PM, CM) effect on the survival probability of some MD using exponential distribution approach. The purpose of this study is to counter the credibility of manufacturer's recommended interval. Minimal and perfect repair assumptions are the main shortcoming of a wide range of maintenance optimization models in the literature and imperfect maintenance is less addressed to assess MEMPs effectiveness.

3.5. Modeling Deterioration. It is the central part of maintenance optimization models. Maintenance excellence is measured by its ability to address the most significant failure mechanisms [44]. Deterioration modeling should match up as close as possible the system's real time to failure. Therefore, many tools were developed in the literature to model deteriorations behaviors that are classified into three categories: black, white, and grey box [42].

Statistical distributions are the easiest and widespread used models among black box category [69] (e.g., normal, exponential, and Weibull) which do not provide any physic 
interpretation of the studied system. Additionally, they depend strongly on failure data availability which is usually not the case of high reliable systems $[67,70]$. Then, white box method is an attractive tool to model component failure behavior with focus on physical properties details of maintained systems (e.g., corrosion, crack) [14]. Nevertheless, the failure mechanism is lacking for several cases and the reliability analytical expression derived usually increases the complexity of the model. Thus, researchers use intermediate stochastic methods (grey box). Referring to [70, 71] works, Markov process is a common approach employed to model either discrete or continuous time stochastic degradations. However, with more complex systems, this model has a disadvantage of state explosion which makes the optimization too complex to solve.

In the same way, numerous other models have been proposed in the literature to overcome modeling deterioration problems. The paper [72] evaluated a multicomponent system performance drawing on Petri net network. The paper [73] assessed a system's dependability in a dynamic hybrid context employing hybrid stochastic automaton (ASH). The paper [74] exploited the Bayesian dynamic network (RBD) to model rail deteriorations reliability. The emergence of conditionbased maintenance instigates the deployment of other tools such as proportional hazard model (PHM) to investigate the influence of covariates on system's degradation [13]. Maintenance strategies shift to predictive making decision using prognostic information has brought about new publications. The paper [16, 17] used gamma process and [75] evaluated modeling approaches for remaining useful life (URL) of deteriorated system.

Even though failure mechanism modeling has been widely used and applied in many industries, its application to the healthcare devices operating context is fairly new. Most of the researches in this area are limited to the reliability assessment of MD early design stages. The paper $[54,68]$ enumerates some well-known reliability models in the concept, design, prototype, and manufacturing phase of MD to attain a high level of safety satisfaction. Yet, $[6,66]$ reported that several facts and figures in relation to patient outcomes are directly or indirectly associated with medical devices reliability and operators errors. The paper [6] provides useful guidelines to improve MD reliability. Thus, Dhillon [6] insisted on using classical methods like general approach, parts counts method, Markov chain, failure mode and effect analysis (FMEA), and fault tree analysis (FTA). Dhillon as well addresses the problem of human error and resumed that reliability engineering has successfully improved systems in the aerospace area and its application to the healthcare domain would generate similar dividends [55].

Work in [56] was the first step to assess the applicability and usefulness of some commonly used age-dependent and repair effect models to repairable MD systems. He concluded that the power-law process is the most convenient for the survival models and the best fitted for repairable devices. Likewise, [32] evaluated and analyzed maintenance strategies effect on the survival probability of some MD using exponential distribution approach. Later, [67] proposes a statistical analysis of MD soft and hard failure data flowing
Nonhomogenous Poisson process (NHPP) with a power-law intensity function.

The results of the above studies contradict the common belief that medical device's failures follow an exponential distribution and that their times between failures (TBF) are independent. Black box models including survival distributions are the most applied methods to evaluate degradation mechanism for medical equipment. Then, other stochastic methods are supposed to be investigated in this domain.

3.6. System Information and Data Sources. Normally, all system information including technical description, its function, and importance is the first aspect covered by maintenance optimization models. The paper [44] stresses that analyzing failure data with system's incomplete information makes possible wrong model and decision. The paper [76] summarizes multicomponent maintenance models based on economic, structural, and stochastic dependencies. These models are also available for different configurations given series, parallel, K-out-of-N, and standby [77]. The paper [65] applied a simple method of decomposition to evaluate medical devices reliability on series-parallel-systems. The paper [67] states that complex repairable MD can be classified into two categories: hard and soft failure components, those are stochastically and economically independent.

There is always an obvious requirement of a reliable and available data to shift from theoretical to applied research [44]. In general, maintenance optimization application calls for three kinds of data: failure, operating, and cost data. Maintenance information system unavailability is often seen the biggest obstacle to overcome the lack of failure data. Moreover, cost data is quite difficult to count, especially indirect maintenance costs. Therefore, many publications have appeared to tackle data uncertainty [78, 79]. The paper [67] proposes a statistical analysis of MD soft and hard failure data presenting a lot of censoring events. In medical environment, equipment tends to be highly reliable which makes scarce and censored failure data the key problem of this domain.

3.7. Optimization Techniques. Once objectives are well identified and all necessary information is collected, useful maintenance optimization algorithms vary according to their ability to find an optimal solution in a minimum time and money. Analytical and numerical methods are the prevalent used methods in the literature [80]. However, they are only applied to simple systems with reduced constraints number. In the case of more complex models, these exact methods are time consuming or sometimes impossible to implement [42]. Indeed, maintenance optimization in real industrial context is usually subjected to several constraints and very complex to resolve. Therefore, many simulation methods were used to overcome this problem. For example, [72] evaluated a multicomponent system performance drawing on Petri net network combined with Monte Carlo simulation. The paper [81] gives an overview of simulation-based optimization and remarks that discrete event simulation (DES) dominates the literature. Although this method gives a solution in a reasonable time, there is no guarantee if this solution is accurate and reliable [42]. Recently, researches are oriented toward a new 
trend of maintenance optimization techniques, called metaheuristics [81]. These evolutionary methods are based on mechanism observed in nature and give an intelligent exploration and exploitation of the optimization problem search space $[46,53,82]$. It is worth mentioning that populationbased heuristics, especially genetic algorithm (GA), are the well-known class of metaheuristics applied in maintenance optimization problems [42, 81].

As mentioned before, maintenance optimization models for medical equipment are still an underexplored area. Based on a mapping review, [41] states that applying mathematical models to optimize maintenance strategies in the healthcare domain is scarce and still in its infancy stage. Besides, the few models proposed in the literature are founded on critical assumptions such as constant failure rate regardless of equipment age, neglected maintenance time, complete maintenance history, and information.

Further, the few publications that appeared in the literature are founded on several simpler assumptions and employ classical optimization methods. The paper [48] proposed several mathematical models to find the optimal periodic inspection interval for MD repairable systems based on minimal maintenance hypothesis. The author used a recursive algorithm to find the solution, which makes the model computationally hard and time consuming. The paper [32] suggested a mixed-integer linear programming to solve an MD maintenance scheduling problem using greedy algorithms.

Premature convergence to local optima is seen the biggest delimitation of the local search algorithms employed in optimization models already presented. These mathematical models are also limited to the assessment of failure rate excluding maintenance effectiveness. Then, taking into account the other assumptions makes the optimization model more complex to solve by a classical exact approach.

3.8. Outputs. Maintenance optimization models yield an assortment of aspects, described in $[44,80]$. The first usual output of these models is a determination of timing decisions (when and how often to inspect, replace, or maintain) $[9,12$, $14,83]$. Secondly, they can serve as a tool to evaluate and compare different maintenance strategies $[11,72,84]$. Optimization models can also provide an optimum maintenance scheduling and planning and help to specify maintenance resources requirements (crew size and composition, spare parts, and outsourcing) [11, 46, 53]. Maintenance optimization models for medical equipment results are principally the determination of an optimal maintenance inspection/replacement interval $[47,48,56]$. The paper [47] evaluates and compares PM to CM strategy and [43] studies the implementation of CBM in healthcare domain compared with the existing (PM and CM) policy. Even so, the assumption of promptly available maintenance resources is regular in the literature and the authors in this research area do not consider logistics in maintenance optimization models.

\section{Discussion and Conclusions}

This work has set sights on assessing the status of research tackling preventive maintenance optimization problems of medical devices. Since not much has been presented in this field, the study was broadened to take account of other research papers which have demonstrated to a large extent the success of advanced maintenance optimization models on other industries. We deeply analyzed ten aspects determining a model of maintenance optimization problem: maintenance policies and actions, maintenance objectives, maintenance effectiveness, modeling deterioration, system information and configuration, data sources, and optimization techniques. The foremost finding of this study is the necessity of further research in maintenance optimization modeling in the healthcare domain, as highlighted by literature gaps detailed above. Our proposal for future effort in this research field is along these lines:

(i) Instead of merely following standards, regulations, and manufacturer's recommendations, healthcare professionals should deploy evidence-based maintenance to learn from comparative maintenance efficiency studies and make required adjustments to maintenance policies and actions, especially, when many manuscripts have showed how maintenance strategies for medical equipment are extensive and counterproductive.

(ii) Reliability centered maintenance and total productive maintenance concepts represent a significant step in "getting the most out" of medical equipment compared with other industries applications and may help medical maintenance service elaborate evidencebased strategies for the betterment of their performance levels.

(iii) Risk-based prioritization methods are widely used only to identify the critical medical devices subject to stringent maintenance program and not for true PM optimization issues. Evidence in the literature points that mathematical modeling is much more flexible than empirical approaches, and medical maintenance would benefit from optimization modeling.

(iv) Hardly any study in medical equipment maintenance has addressed condition based maintenance policy compared with preventive and corrective ones. Further research in this field should measure outcomes of predictive maintenance including prognostics.

(v) Regarding previous few works in medical devices optimization modeling, multiobjective optimization models remain an underexplored area. And less attention was paid to determine the key objective criteria to avoid inappropriate maintenance model leading to suboptimal solutions.

(vi) Minimal and perfect repair assumptions are the main shortcoming of a wide range of maintenance optimization models in the literature. Imperfect maintenance is less addressed to asses MEMPs effectiveness.

(vii) Black box models including survival distributions are the most applied methods to evaluate degradation mechanism for medical equipment. Other stochastic methods are supposed to be investigated in this domain. 
TABLE 1

\begin{tabular}{|c|c|c|}
\hline Ref & Theme & Description \\
\hline$[54]$ & Empirical & Reliability in the medical device industry \\
\hline$[55]$ & Empirical & Medical device reliability \\
\hline$[23]$ & Prioritization & Smart-IPM tool for the MD PM \\
\hline$[56]$ & Optimization & Data-based modeling of the failure rate of repairable equipment \\
\hline$[24]$ & Prioritization & A practical, risk-based approach to $\mathrm{PM}$ program management \\
\hline$[57]$ & Prioritization & JCAHO’s equipment inclusion criteria revisited \\
\hline$[58]$ & Prioritization & Analyzing (PM) inspection data by FTA analysis methodology \\
\hline [59] & Empirical & The theory and practice of preventive maintenance \\
\hline$[60]$ & Empirical & Interview with Larry Fennigkoh \\
\hline$[61]$ & Prioritization & MD risk-based evaluation and maintenance using FTA \\
\hline$[25]$ & Prioritization & A fuzzy approach for medical equipment replacement planning \\
\hline$[62]$ & Empirical & A practicum for biomedical engineering \\
\hline$[63]$ & Empirical & Decoding the PM puzzle \\
\hline$[64]$ & Empirical & Medical equipment management manual \\
\hline$[31]$ & Empirical & Manufacturer-recommended PM intervals \\
\hline$[37]$ & Empirical & Reducing equipment downtime a new line of attack \\
\hline$[26]$ & Prioritization & Multicriteria model to support the MD replacement \\
\hline$[22]$ & Empirical & Measuring maintenance effectiveness with failure codes \\
\hline$[65]$ & Empirical & Measuring the efficiency of medical equipment \\
\hline$[49]$ & Prioritization & Comparing maintenance strategies using failure codes \\
\hline$[6]$ & Empirical & Medical equipment reliability: a review \\
\hline$[66]$ & Empirical & Enhancing patient safety using failure code analysis \\
\hline$[67]$ & Empirical & Reliability analysis of maintenance data for complex MD \\
\hline$[48]$ & Optimization & Reliability and maintenance of medical devices \\
\hline [47] & Optimization & Evidence-based mathematical maintenance model for MD \\
\hline$[39]$ & Empirical & Implementation of Six Sigma on corrective maintenance \\
\hline$[68]$ & Empirical & Reliable design of medical devices \\
\hline$[41]$ & Empirical & Medical device maintenance outsourcing: A mapping review \\
\hline [5] & Empirical & Medical equipment maintenance: management and oversight \\
\hline$[32]$ & Empirical & The effect of maintenance on the survival of medical equipment \\
\hline$[38]$ & Empirical & A study of current maintenance strategies and the reliability \\
\hline$[43]$ & Optimization & Case study of cost benefits of condition based maintenance \\
\hline$[29]$ & Prioritization & A fuzzy logic model for medical equipment risk classification \\
\hline$[21]$ & Empirical & Medical devices inspection and maintenance, a review \\
\hline$[28]$ & Prioritization & A fuzzy risk-based maintenance framework for MD prioritization \\
\hline
\end{tabular}

(viii) Different kind of configurations and system's components dependencies are ought to be considered to make optimization models much more realistic.

(ix) Maintenance resources requirements (crew size and composition, spare parts, outsourcing, and logistics issues) should be further included in optimization models for medical equipment to create more pragmatic decision-making structure.

(x) Metaheuristic algorithms found their success in many other industries. They can be useful for medical equipment maintenance optimization to overcome the weaknesses of classical methods already employed.

\section{Appendix}

See Table 1.

\section{Competing Interests}

The authors declare that there is no conflict of interests regarding the publication of this paper.

\section{References}

[1] A. H. C. Tsang, "Strategic dimensions of maintenance management," Journal of Quality in Maintenance Engineering, vol. 8, no. 1, pp. 7-39, 2002. 
[2] B. Al-Najjar, "The lack of maintenance and not maintenance which costs: a model to describe and quantify the impact of vibration-based maintenance on company's business," International Journal of Production Economics, vol. 107, no. 1, pp. 260273, 2007.

[3] D. Maletič, M. Maletič, B. Al-Najjar, and B. Gomišček, "The role of maintenance in improving company's competitiveness and profitability: a case study in a textile company," Journal of Manufacturing Technology Management, vol. 25, no. 4, Article ID 17110934, pp. 441-456, 2014.

[4] A. T. de Almeida, C. A. V. Cavalcante, M. H. Alencar et al., Multicriteria and Multiobjective Models for Risk, Reliability and Maintenance Decision Analysis, vol. 231 of International Series in Operations Research \& Management Science, Springer, Berlin, Germany, 2015.

[5] B. Wang, "Medical equipment maintenance: management and oversight," Synthesis Lectures on Biomedical Engineering, vol. 7, no. 2, pp. 1-85, 2012.

[6] B. S. Dhillon, "Medical equipment reliability: a review, analysis methods and improvement strategies," International Journal of Reliability, Quality and Safety Engineering, vol. 18, no. 4, pp. 391403, 2011.

[7] M. Arturo, Optimisation de la Disponibilité des Systèmes Assujettis à la Maintenance Imparfaite, 2008.

[8] S. H. Nggada, Multi-objective system optimisation with respect to availability, maintainability and cost [Ph.D. thesis], Department of Computer Science, The University of Hull, 2012.

[9] H. C. Oteyaka, "Optimal Cost and Availability Replacement Models for Multi-Component Systems," 2008.

[10] W. I. Soro, "Modélisation et Optimisation Des Performances et de La Maintenance Des Systèmes Multi-États," 2011.

[11] F. Besnard, On Maintenance Optimization for Offshore Wind Farms, Chalmers University of Technology, 2013.

[12] E. Deloux, Politiques de Maintenance Conditionnelle Pour un Système à Dégradation Continue Soumis à un Environnement Stressant, 2008.

[13] B. R. Wu, "Condition Based Maintenance Optimization Using Data Driven Methods," 2013.

[14] S. Yacine, "Optimisation Des Methodes D'inspection Des Pipes," 2014.

[15] A. Van Horenbeek, Information-Based Maintenance Optimization with Focus on Predictive Maintenance, Faculty of Engineering Science, 2013.

[16] K. T. Huynh, Quantification de L'apport de L'Information de Surveillance Dans La Prise de Décision En Maintenance, Université de Technologie de Troyes, Troyes, France, 2011.

[17] N. F. G. van Dorst, I. J. B. F. Adan, H. Peng, J. A. M. Melssen, and R. W. F. J. M. Lemmens, Component condition monitoring and remaining useful life prediction [Master of Science Thesis], Department of Industrial Engineering, Eindhoven University of Technology, Eindhoven, The Netherlands, 2014.

[18] A. Van Horenbeek, L. Pintelon, and P. Muchiri, "Maintenance optimization models and criteria," International Journal of Systems Assurance Engineering and Management, vol. 1, no. 3, pp. 189-200, 2010.

[19] R. P. Nicolai and R. Dekker, "A review of multi-component maintenance models," in Proceedings of the European Safety and Reliability Conference, pp. 289-296, 2007.

[20] A. Garg and S. G. Deshmukh, "Maintenance management: literature review and directions," Journal of Quality in Maintenance Engineering, vol. 12, no. 3, pp. 205-238, 2006.
[21] A. Jamshidi, S. A. Rahimi, D. Ait-Kadi, and A. R. Bartolome, "Medical devices inspection and maintenance-a literature review," in Proceedings of the IIE Annual Conference, January 2014.

[22] B. Wang, J. Fedele, B. Pridgen et al., "Evidence-based maintenance: part I: measuring maintenance effectiveness with failure codes," Journal of Clinical Engineering, vol. 35, no. 3, pp. 132-144, 2010.

[23] R. B. Arslan and Y. Ulgen, "Smart-IPM: an adaptive tool for the preventive maintenance of medical equipment," Annual Reports of the Research Reactor Institute, Kyoto University, vol. 4, pp. 3950-3953, 2001.

[24] M. Ridgway, "Classifying medical devices according to their maintenance sensitivity: a practical, risk-based approach to PM program management," Biomedical Instrumentation and Technology, vol. 35, no. 3, pp. 167-176, 2001.

[25] G. Mummolo, L. Ranieri, V. Bevilacqua, and P. Galli, "A fuzzy approach for medical equipment replacement planning," in Proceedings of the 3 rd International Conference on Maintenance and Facility Management, pp. 229-235, 2007.

[26] L. M. J. De Figueiredo, Multicriteria model to support the replacement of hospital medical equipment [M.S. thesis], Instituto Superior Técnico, Lisboa, Portugal, 2009.

[27] S. Taghipour, D. Banjevic, and A. K. S. Jardine, "Prioritization of medical equipment for maintenance decisions," Journal of the Operational Research Society, vol. 62, no. 9, pp. 1666-1687, 2011.

[28] A. Jamshidi, S. A. Rahimi, D. Ait-Kadi, and A. Ruiz, "A comprehensive fuzzy risk-based maintenance framework for prioritization of medical devices," Applied Soft Computing, vol. 32, pp. 322-334, 2015.

[29] B. Tawfik, B. K. Ouda, and Y. M. Abd El Samad, "A fuzzy logic model for medical equipment risk classification," Journal of Clinical Engineering, vol. 38, no. 4, pp. 185-190, 2013.

[30] A. T. de Almeida, R. J. Ferreira, and C. A. Cavalcante, "A review of the use of multicriteria and multi-objective models in maintenance and reliability," IMA Journal of Management Mathematics, vol. 26, no. 3, pp. 249-271, 2015.

[31] M. G. Ridgway, "Manufacturer-recommended PM intervals: is it time for a change?" Biomedical Instrumentation and Technology, vol. 43, no. 6, pp. 498-500, 2009.

[32] A. B. Khalaf, Y. Hamam, Y. Alayli, and K. Djouani, “The effect of maintenance on the survival of medical equipment," Journal of Engineering, Design and Technology, vol. 11, no. 2, pp. 142-157, 2013.

[33] N. H. Kim, H. Wang, and N. V. Queipo, "Adaptive reduction of random variables using global sensitivity in reliability-based optimisation," International Journal of Reliability and Safety, vol. 1, no. 1-2, pp. 102-119, 2006.

[34] J. Moubray, Reliability Centered Maintenance, Industrial Press, New York, NY, USA, 1997.

[35] S. Nakajima, Introduction to TPM: Total Productive Maintenance, Productivity Press, Cambridge, Mass, USA, 1988.

[36] A. Shahin, E. Pourjavad, and H. Shirouyehzad, "Selecting optimum maintenance strategy by analytic network process with a case study in the mining industry," International Journal of Productivity and Quality Management, vol. 10, no. 4, pp. 464483, 2012.

[37] M. Ridgway, L. R. Atles, and A. Subhan, Reducing Equipment Downtime: A New Line of Attack, 2009.

[38] K. A. Mkalaf, P. Gibson, and J. Flanagan, "A study of current maintenance strategies and the reliability of critical medical 
equipment in hospitals in relation to patient outcomes," International Journal of Social, Behavioral, Educational, Economic, Business and Industrial Engineering, vol. 7, no. 10, pp. 1383-1390, 2013.

[39] Majeda, "Implementation of Six Sigma on Corrective Maintenance at the Directorate of Biomedical Engineering in the Jordanian Ministry of Health," 2012.

[40] D. Troyer, Strategic Plant Reliability Management Course Book, 2006.

[41] A. Miguel Cruz and A. Maria Rios Rincon, "Medical device maintenance outsourcing: have operation management research and management theories forgotten the medical engineering community? A mapping review," European Journal of Operational Research, vol. 221, no. 1, pp. 186-197, 2012.

[42] H. Mahfoud, "Optimisation des Stratégies de Maintenance D'un Système Complexe-Analyse Bibliographique," in Congrès International du Génie Industriel et Management des Systèmes (CIGIMS '15), p. 16, Fes, Morocco, 2015, http://abdennebi.voila .net/ARTICLES/T12_R143.pdf.

[43] Q. Zhang, "Case study of cost benefits of condition based maintenance used in medical devices," in Proceedings of the 59th Annual Reliability and Maintainability Symposium (RAMS '13), pp. 1-5, Orlando, Fla, USA, January 2013.

[44] R. Dekker, "Applications of maintenance optimization models: a review and analysis," Reliability Engineering \& System Safety, vol. 51, no. 3, pp. 229-240, 1996.

[45] S. Gasmi and N. Mannai, "Optimization problems of costs in a multistate system with imperfect maintenance," Journal of Quality and Reliability Engineering, vol. 2014, Article ID 592527, 10 pages, 2014.

[46] A. O. Olumuyiwa, A decision support model to improve rolling stock maintenance scheduling based on reliability and cost [M.S. thesis], Stellenbosch University, 2014.

[47] A. Khalaf, K. Djouani, Y. Hamam, and Y. Alayli, "Evidencebased mathematical maintenance model for medical equipment," in Proceedings of the 2010 International Conference on Electronic Devices, Systems and Applications, pp. 222-226, IEEE, Kuala Lumpur, Malaysia, April 2010.

[48] S. Taghipour, "Reliability and Maintenance of Medical Devices," 2011.

[49] B. Wang, J. Fedele, B. Pridgen et al., "Evidence-based maintenance-part II: comparing maintenance strategies using failure codes," Journal of Clinical Engineering, vol. 35, no. 4, pp. 223230, 2010.

[50] A. T. de Almeida, "Multicriteria model for selection of preventive maintenance intervals," Quality and Reliability Engineering International, vol. 28, no. 6, pp. 585-593, 2012.

[51] L. Doyen and O. Gaudoin, "Modélisation de l'efficacité de la maintenance des systèmes réparables-synthèse bibliographique," Contract Report T50L47 F 555, 2004.

[52] H. Wang, "A survey of maintenance policies of deteriorating systems," European Journal of Operational Research, vol. 139, no. 3, pp. 469-489, 2002.

[53] R. S. Al Hosseini, Ant Colony for Optimization of Imperfect Preventive Maintenance for Multi-State Systems, Université Laval, 2006.

[54] V. Hegde, "Reliability in the medical device industry," in Handbook of Performability Engineering, pp. 997-1009, Springer, Berlin, Germany, 2000.

[55] B. S. Dhillon, Medical Device Reliability and Associated Areas, CRC Press, New York, NY, USA, 2000.
[56] R. D. Baker, "Data-based modeling of the failure rate of repairable equipment," Lifetime Data Analysis, vol. 7, no. 1, pp. 65-83, 2001.

[57] B. Wang and W. P. Rice, "JCAHO's equipment inclusion criteria revisited-application of statistical sampling technique," Journal of Clinical Engineering, vol. 28, no. 1, pp. 37-48, 2003.

[58] M. Ridgway, "Analyzing planned maintenance (PM) inspection data by Failure Mode and Effect Analysis methodology," Biomedical Instrumentation and Technology, vol. 37, no. 3, pp. 167-179, 2003.

[59] W. A. Hyman, "The theory and practice of preventive maintenance," Journal of Clinical Engineering, vol. 28, no. 1, pp. 31-36, 2003.

[60] B. Wang, "Fennigkoh and Smith model for inclusion criteria: 15-Year retrospective: Interview with Larry Fennigkoh," Journal of Clinical Engineering, vol. 31, no. 1, pp. 26-30, 2006.

[61] W. P. Rice, "Medical device risk based evaluation and maintenance using fault tree analysis," Biomedical Instrumentation \& Technology, vol. 41, no. 1, pp. 76-82, 2007.

[62] L. R. Atles, A Practicum for Biomedical Engineering and Technology Management Issues, Kendall/Hunt Publishing, 2008.

[63] M. Ridgway, "Decoding the PM puzzle," in Proceedings of the 20th Biomedical Symposium, 2008.

[64] R. H. Stiefel, Medical Equipment Management Manual, 2009.

[65] P. H. Tsarouhas, "Measuring the efficiency of medical equipment," World Academy of Science, Engineering and Technology, vol. 4, no. 44, pp. 340-345, 2010.

[66] B. Wang, J. Fedele, B. Pridgen et al., "Evidence-based maintenance: part III, enhancing patient safety using failure code analysis," Journal of Clinical Engineering, vol. 36, no. 2, pp. 7284, 2011.

[67] S. Taghipour, D. Banjevic, and A. K. S. Jardine, "Reliability analysis of maintenance data for complex medical devices," Quality and Reliability Engineering International, vol. 27, no. 1, pp. 7184, 2011.

[68] R. C. Fries, Reliable Design of Medical Devices, CRC Press, New York, NY, USA, 2012.

[69] L. Pintelon and F. Van Puyvelde, Maintenance Decision Making, Acco, 2006.

[70] C. Letot and P. Dehombreux, "Actualized reliability model based on degradation data and maintenance optimization," in Proceedings of the 2nd IFAC Workshop on Advanced Maintenance Engineering, Services and Technology (A-MEST '12), pp. 211-216, Seville, Spain, November 2012.

[71] W. Lair, Modélisation Dynamique de Systèmes Complexes Pour le Calcul de Grandeurs Fiabilistes et L'Optimisation de la Maintenance, Université de Pau et des Pays de l’Adour, 2011.

[72] V. Zille, "Modélisation et Évaluation Des Stratégies de Maintenance Complexes Sur Des Systèmes Multi-Composants," 2009.

[73] G. A. P. Castaneda, Evaluation Par Simulation de La Sûreté de Fonctionnement de Systèmes En Contexte Dynamique Hybride, Institut National Polytechnique de Lorraine, 2009.

[74] R. Donat, "Modélisation de La Fiabilité et de La Maintenance Par Modèles Graphiques Probabilistes: Application À La Prévention Des Ruptures de Rail,” 2009.

[75] Z. Tian, L. Wong, and N. Safaei, "A neural network approach for remaining useful life prediction utilizing both failure and suspension histories," Mechanical Systems and Signal Processing, vol. 24, no. 5, pp. 1542-1555, 2010. 
[76] R. P. Nicolai and R. Dekker, "Optimal maintenance of multicomponent systems: a review," in Complex System Maintenance Handbook, K. A. H. Kobbacy and D. N. P. Murthy, Eds., Springer Series in Reliability Engineering, pp. 263-286, Springer, New York, NY, USA, 2008.

[77] I. S. Triantafyllou, "Consecutive-type reliability systems: an overview and some applications," Journal of Quality and Reliability Engineering, vol. 2015, Article ID 212303, 20 pages, 2015.

[78] R. Azimi and F. Yaghmaei, "Bayesian estimation based on Rayleigh progressive type II censored data with binomial removals," Journal of Quality and Reliability Engineering, vol. 2013, Article ID 896807, 6 pages, 2013.

[79] K. Sadeghzadeh and N. Fard, "Variable selection methods for right-censored time-to-event data with high-dimensional covariates," Journal of Quality and Reliability Engineering, vol. 2015, Article ID 795154, 9 pages, 2015.

[80] A. K. S. Jardine and A. H. C. Tsang, Maintenance, Replacement, and Reliability: Theory and Applications, CRC Press, New York, NY, USA, 2013.

[81] A. Alrabghi and A. Tiwari, "State of the art in simulationbased optimisation for maintenance systems," Computers and Industrial Engineering, vol. 82, pp. 167-182, 2015.

[82] A. A. Elhadidy, E. E. Elbeltagi, and M. A. Ammar, "Optimum analysis of pavement maintenance using multi-objective genetic algorithms," HBRC Journal, vol. 11, no. 1, pp. 107-113, 2015.

[83] Y.-T. Tsai, K.-S. Wang, and L.-C. Tsai, "A study of availabilitycentered preventive maintenance for multi-component systems," Reliability Engineering \& System Safety, vol. 84, no. 3, pp. 261-270, 2004.

[84] V. Murth, A simulation based approach for determining maintenance strategies [M.S. thesis], University of Tennessee, 2003. 


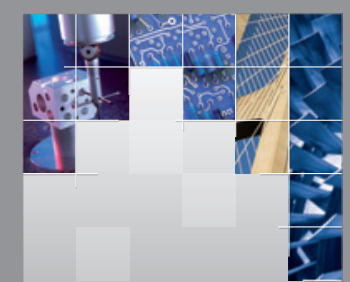

\section{Enfincering}
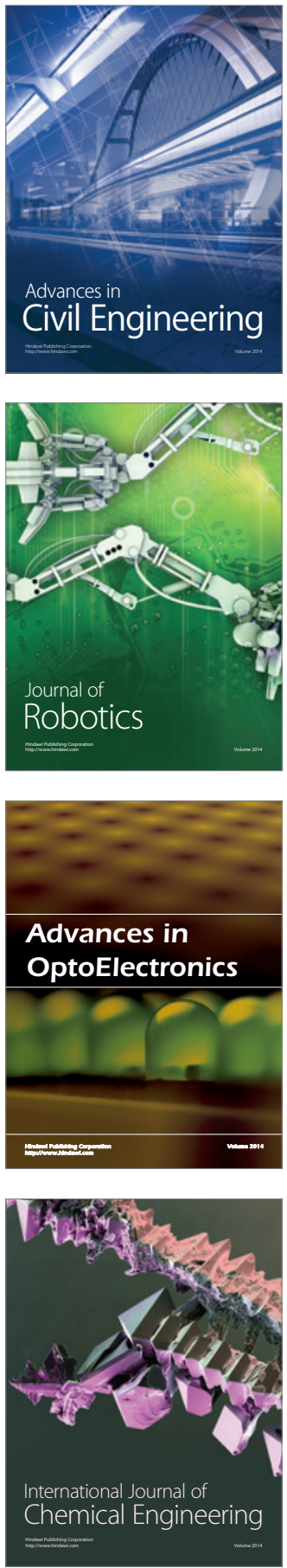

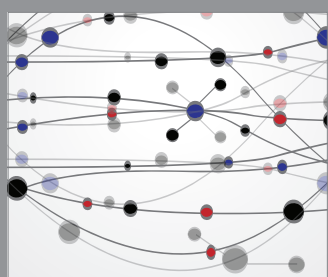

The Scientific World Journal

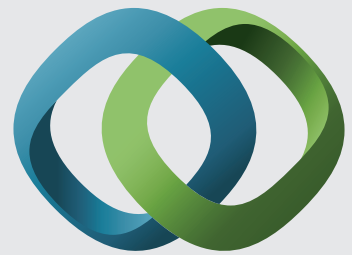

\section{Hindawi}

Submit your manuscripts at

http://www.hindawi.com
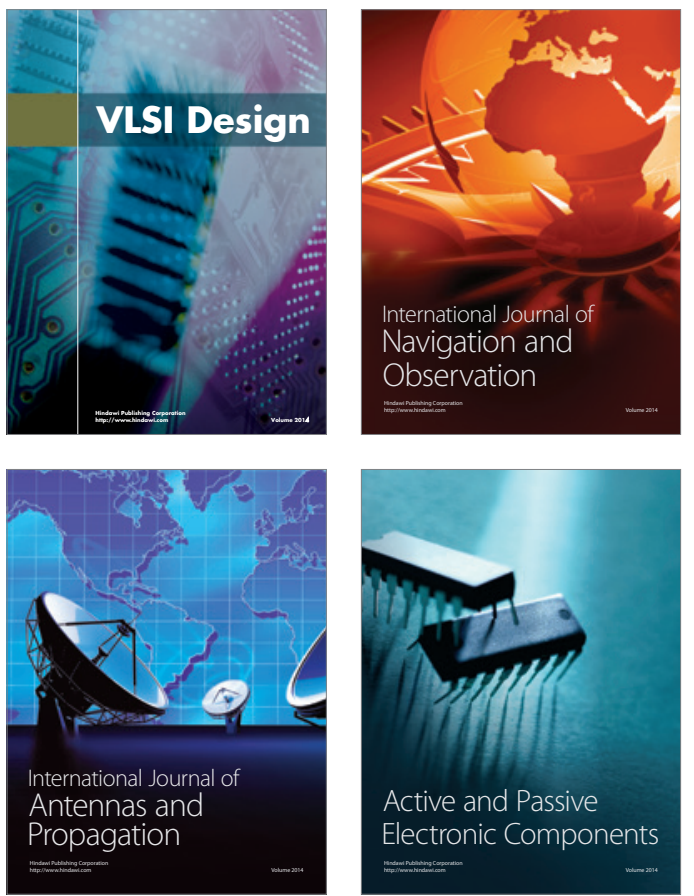
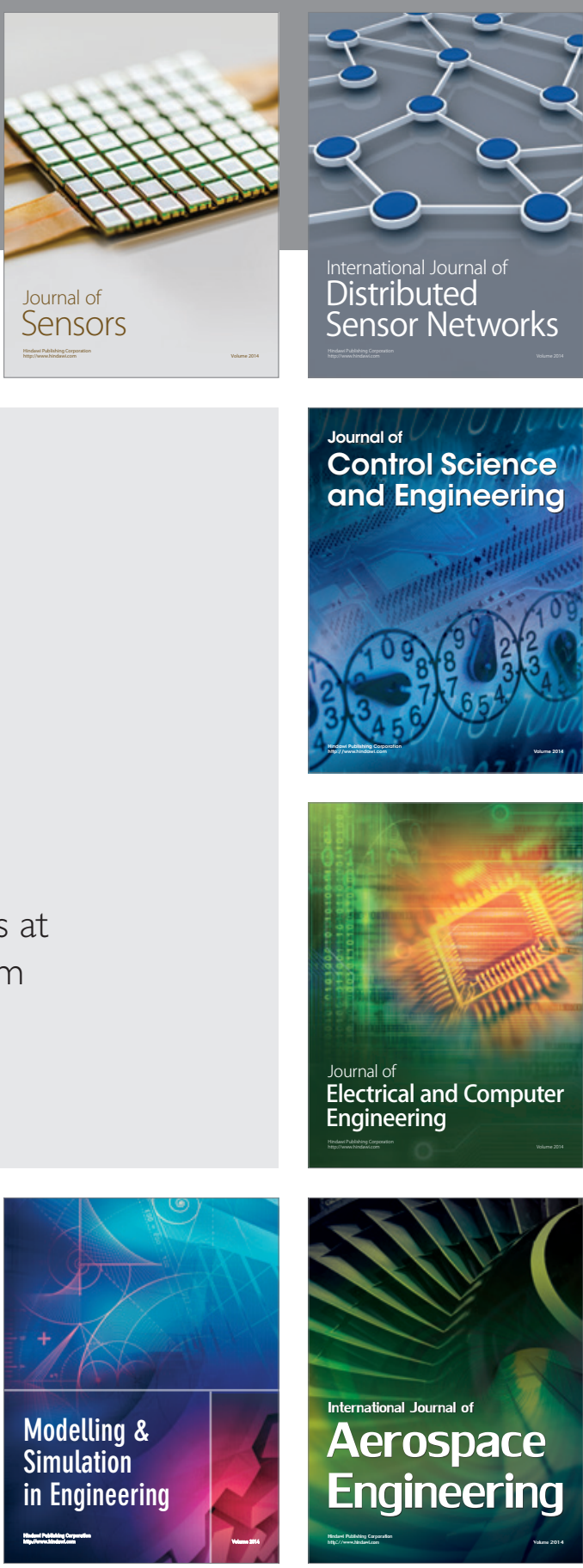

International Journal of

Distributed

Sensor Networks

Journal of

Control Science

and Engineering
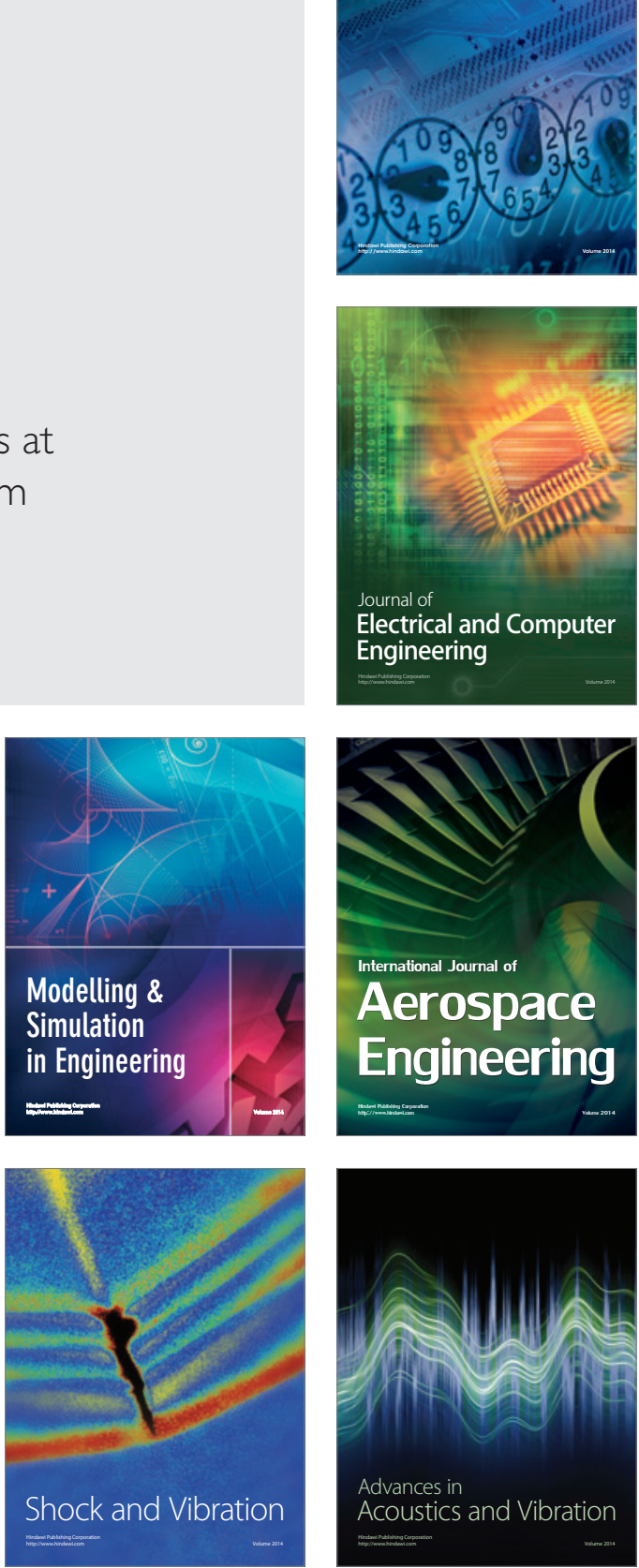